Article

\title{
Effects of Dietary Vitamin E Supplementation in Bladder Function and Spasticity during Spinal Cord Injury
}

\author{
Kathia Cordero, Gemma G. Coronel, Miguel Serrano-Illán, Jennifer Cruz-Bracero, \\ Johnny D. Figueroa ${ }^{(D)}$ and Marino De León* ${ }^{(D)}$
}

Center for Health Disparities and Molecular Medicine, Department of Basic Sciences, Loma Linda University School of Medicine, Loma Linda, CA 92350, USA; kacordero@llu.edu (K.C.); gcoronel@ucsc.edu (G.G.C.); mserranoillan@llu.edu (M.S.-I.); jcb5288@gmail.com (J.C.-B.); jfigueroa@llu.edu (J.D.F.)

* Correspondence: madeleon@llu.edu; Tel.: +1-(909)-558-8777

Received: 26 January 2018; Accepted: 23 February 2018; Published: 26 February 2018

\begin{abstract}
Traumatic spinal cord injury (SCI) results in debilitating autonomic dysfunctions, paralysis and significant sensorimotor impairments. A key component of SCI is the generation of free radicals that contributes to the high levels of oxidative stress observed. This study investigates whether dietary supplementation with the antioxidant vitamin E (alpha-tocopherol) improves functional recovery after SCI. Female adult Sprague-Dawley rats were fed either with a normal diet or a dietary regiment supplemented with vitamin E (51 IU/g) for eight weeks. The rats were subsequently exposed either to a contusive SCI or sham operation, and evaluated using standard functional behavior analysis. We report that the rats that consumed the vitamin E-enriched diet showed an accelerated bladder recovery and significant improvements in locomotor function relative to controls, as determined by residual volumes and Basso, Beatie, and Bresnaham BBB scores, respectively. Interestingly, the prophylactic dietary intervention did not preserve neurons in the ventral horn of injured rats, but it significantly increased the numbers of oligodendrocytes. Vitamin E supplementation attenuated the depression of the H-reflex (a typical functional consequence of SCI) while increasing the levels of supraspinal serotonin immunoreactivity. Our findings support the potential complementary use of vitamin $\mathrm{E}$ to ameliorate sensory and autonomic dysfunctions associated with spinal cord injury, and identified promising new cellular and functional targets of its neuroprotective effects.
\end{abstract}

Keywords: spinal cord injury; Vitamin E; bladder dysfunction; H-reflex; oligodendrocytes

\section{Introduction}

Primary mechanical injury to the spinal cord sets in motion a complex cascade of secondary harmful events that result in serious neurological dysfunction and paralysis. Following the initial lesion, events associated with a secondary injury can last several days and weeks after injury. Disorders associated with the secondary injury include dramatic metabolic alterations [1-9], a general increase in oxidative stress and inflammation [10-20], demyelination [20-25], and apoptosis [26-29]. During the first week after injury there is an extensive loss of neurons and oligodendrocyte [23,28-33], lipid peroxidation [10,34], and axon degeneration [14]. The production of free radicals during this period is believed to contribute to these detrimental outcomes by disrupting cell membranes, causing organelle dysfunction, and disturbing calcium homeostasis [34]. The free radical production peaks at $12 \mathrm{~h}$ after the initial injury and it remains elevated for at least 1 week after injury. Examples of elevated free radicals after injury are hydrogen peroxide, hydroxyl radical, and peroxynitrite radical $[14,35]$. Previous studies have shown a reduced antioxidant defense after SCI [36] and antioxidant agents such as tempol have shown to be neuroprotective in the context of SCI [37]. 
Previous reports from our laboratory showed that dietary prophylaxis with omega-3 lipids is protective during SCI. For instance, dietary omega-3 polyunsaturated fatty acids (O3PUFAs) modulated multiple pathways that contribute to secondary acute and chronic damages following SCI [38,39]. Administration of O3PUFAs restored the spinal cord lipid homeostasis, confers neuroprotection, prevents sensorimotor dysfunction and neuropathic pain, and facilitates locomotor recovery following acute and chronic SCI when administered before and during SCI [38-40]. Another nutrient with demonstrated antioxidant capability that could be important in stimulating recovery following SCI injury is vitamin E. Previous studies using dietary vitamin E supplementation for 5 days prior to the SCI in cats found a reduction of arachidonate and prostanoids [41] associated with less ischemia [42] and enhanced locomotion recovery [43]. Further, dietary vitamin E for 8 weeks before SCI decreased reactive oxygen species (ROS) while improved locomotion, blood flow and spinal cord evoked potentials, and decreased ROS in rats [44]. While these studies did not use the standardized scale to measure locomotion after SCI, the Basso, Beattie, and Bresnahan (BBB) scale, their findings provided support for a promising neuroprotective role of vitamin E. Further, dietary vitamin E supplementation for 14 days after injury was shown to improve BBB scores $[45,46]$ potentially involving the inhibition of lipid peroxidation products such as thiobarbituric acid reactive substances and malondialdehyde $[44,47,48]$. Thus, prior studies suggest a neuroprotective role of vitamin E during SCI, but little is known about potential targets, primary cellular processes involved and whether it can affect other primary functions affected by SCI. For instance, it is unknown whether dietary prophylaxis with vitamin E can specifically address specific impairments associated with SCI such as bladder dysfunction and spasticity. These processes can be especially sensitive to oxidative stress, serotonin levels or adequate number of oligodendrocyte. The present study evaluates the effects of two months dietary exposure to vitamin E supplementation on selected physiological outcomes and examined potential mechanisms. The underlying hypothesis of the current study is that a balanced antioxidant dietary regimen containing adequate levels of vitamin E may enhance the ability of the spinal cord to response to traumatic injury. The data suggest that dietary vitamin E supplementation significantly improved BBB locomotor scores following SCI. Further, we also report for the first time that prophylactic vitamin $\mathrm{E}$ administration stimulates bladder recovery, inhibited H-reflex depression, supraspinal serotonin levels and preserved oligodendrocytes survival.

\section{Materials and Methods}

\subsection{Animals}

Experimental procedures were compliant with the Loma Linda University School of Medicine regulations and institutional guidelines consistent with the National Institutes of Health Guide for the Care and Use of Laboratory Rats. All animal work reported in this manuscript was performed under the approval the Loma Linda University Health Institutional Animal Care and Use Committee approval number 8170021. A total of 60 female Sprague-Dawley rats weighing 182-212 g were acquired from Charles River Laboratories (Portage, MI, USA). The female rats were housed in individual cages with food and water ad libitum with alternated exposure of light and dark periods of $12 \mathrm{~h}$.

\subsection{Study Design}

The female rats were acclimatized for 1 week after arrival at the animal care facility and were randomly divided into two main groups: (Group 1) rats on the control diet $(n=30)$ and (Group 2) rats on the vitamin E-enriched diet $(n=30)$ (Figure 1). After 8 weeks, the rats were further categorized based on their dietary and surgical interventions: Group 1a was the control diet/sham operated group $(n=15)$; Group 1b was the control diet/spinal cord injured group $(n=15)$; Group 2a was the vitamin E-enriched diet/sham operated group $(n=15)$; and Group $2 \mathrm{~b}$ was the vitamin E-enriched diet/spinal cord injured group $(n=15)$. Dietary interventions were continued after surgery for 1 week post-operation (wpo). During the first week after operation functional recovery and behavioral analysis 
was performed in a blinded manner. Spinal cord tissue was collected for analyses at 1 wpo. We opted for not including a group with a vitamin-E enriched diet after injury only because it has been shown the number of pellets eaten the week following spinal cord injury, the acute phase, substantially decreases $[39,40]$. In a setting where the sub-acute and/or chronic effects of a vitamin-E enriched diet post injury were being studied, such group would definitely contribute to the study, but not in our acute phase, study.

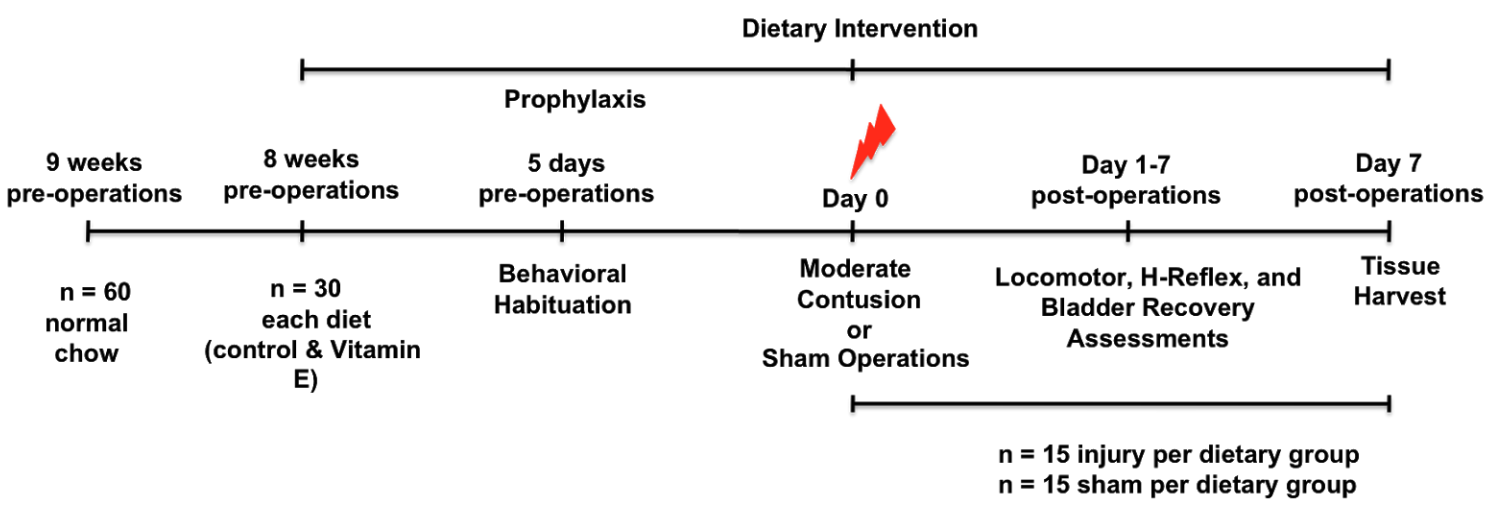

Figure 1. Timeline showing the vitamin E diet supplementation schedule and the time points of behavioral assays, surgical procedures, and tissue sample collection.

\subsection{Diets}

American Institue of Nutrition (AIN)-93G-based custom isocaloric diet formulations were prepared with modified fat compositions (Bio-Serv, Frenchtown, NJ, USA). The amount of dietary fat was supplied as either soybean oil (control diet) or vitamin E-enriched diet and it was approximately $6 \%$ of dry weight. They were both stored in a refrigerated area. Gas chromatography and mass spectrometry analysis showed principal nutrients in the diet as follow: (i) the amount of vitamin $\mathrm{E}$ in the control diet was $0.0816 \mathrm{IU} / \mathrm{g}$ and the vitamin E-enriched diet had $51 \mathrm{IU} / \mathrm{g}$; (ii) total saturated fat was $1.13 \mathrm{~g} / 100 \mathrm{~g}$ and $1.00 \mathrm{~g} / 100 \mathrm{~g}$, total monounsaturated fat was $1.61 \mathrm{~g} / 100 \mathrm{~g}$ and $1.49 \mathrm{~g} / 100 \mathrm{~g}$, total polyunsaturated fat was $4.09 \mathrm{~g} / \mathrm{g}$ and $4.34 \mathrm{~g} / \mathrm{g}$ for control diet and vitamin E-enriched diet, respectively; (iii) the percentage for kcal carbohydrates was 64.7 and 60.5 , the percentage for kcal protein was 18.8 and 21.1 , and the percentage for kcal fat was $16.5 \%$ and $18.4 \%$ for control diet and vitamin E-enriched diet, respectively. During the study rats consumed 15-20 pellets per day. Each pellet weighted approximately $1 \mathrm{~g}$ and it contained $51 \mathrm{IU} / \mathrm{g}$ of vitamin E. We calculate that each rat consumed 765-1020 IU of vitamin E per day. The amount of vitamin E that has been shown to slow down disease progression in Alzheimer's disease in human studies is 2000 IU per day (REF [49-51]. The relationship between how many vitamin E IUs are required for a protective effect in rats vs. humans is not linear since the average rat weight is $0.3 \mathrm{~kg}$ and the average human weight is $70 \mathrm{~kg}$. This can be explained by the higher absolute energy expenditure in rats $(600 \mathrm{~kJ}$ per $\mathrm{kg}$ BW in a $0.2-\mathrm{kg}$ rat) compared to humans (138 kJ per kg BW in a 70-kg human). For more details on the metabolic weight relationship between rats and human, please see our previous publication for a more extensive explanation $[39,40])$.

\subsection{Surgical and Post-Operative Procedures}

The female rats were on dietary pretreatment for eight weeks. Following the treatment, the rats were anesthetized with a combination of ketamine/xylazine $(80 \mathrm{mg} / \mathrm{kg}$ and $10 \mathrm{mg} / \mathrm{kg}$, respectively). The New York University (NYU) Impactor was used to generate the spinal cord lesions [52]. This device causes the necessary trauma to induce bladder dysfunction, which suggests this model is appropriate for evaluating the therapeutic potential of our intervention $([53,54])$. The procedure includes exposing the spinal cord by removing the skin and the muscles overlying the spinal column. Laminectomy was performed at the T9-T10 level and the T8 and T12 spinal processes were clamped to the Impactor 
exposing the dorsal surface of the spinal cord. Next, the dorsal surface was then subjected to weight drop impact with a $10 \mathrm{-g}$ rod released from a height of $12.5-\mathrm{mm}$. Sham rats were not subjected to weight drop impact and only received a laminectomy. The female rats body temperature was maintained at $37{ }^{\circ} \mathrm{C}$ during the whole procedure. After laminectomy or weight drop impact, muscle layers were carefully sutured and skin layers closed. Crede's maneuver was performed three times per day to express the bladders of the injured rats until voiding reflexes were restored. All rats were injected twice per day with Cefazolin (from Bristol Myers Squibb, New York, NY, USA; $25 \mathrm{mg} / \mathrm{kg}$, s.q.) for 5 consecutive days and Buprenex ${ }^{\circledR}($ also known as buprenorphine; from Reckett and Colman Pharmaceuticals, Inc. Richmond, VA, USA; $0.05 \mathrm{mg} / \mathrm{kg}$, s.q.) for 3 consecutive days. Rats were sacrificed 1 week post-operation and the spinal cord tissue was dissected and collected for immunohistochemical analysis.

\subsection{Behavioral Evaluation of Spontaneous Locomotion}

The Basso-Beattie-Bresnahan (BBB) scale is a 22-point (0-21) measurement scale that evaluate the rat's spontaneous open-field locomotion [55]. First, the rats were acclimatized in an empty-plastic black pool simulating an open field environment for five daily sessions 1 week before SCI. After SCI, rats were videotaped weekly in the open field locomotion test. In a blind manner, two observers independently assessed: (1) locomotive function, (2) joint movement, (3) paw placement and rotation, (4) paw coordination, (5) tail position, and (6) trunk position and stability. The average score from both blind observers for each hind paw was used for analyses. According to this measurement scale, a score of 0 is given to a completely paralyzed rat, scores between 1 and 8 are given to rats with increasing joint movements without weight support (recovery stage 1), scores between 9 and 13 are given to rats with abnormal locomotion that are able to produce weight supported steps (recovery stage 2), scores between 14 and 20 are given to rats that have reached graded coordination patterns, paw position, and trunk stability (recovery stage 3), and a score of 21 is given to normal (and sham) rats with no dysfunction in locomotion.

\subsection{H-Reflex Recording}

The rats were placed on a heated (approximately $37^{\circ} \mathrm{C}$ ) metal platform. The Hoffmann's reflex (H-reflex) was recorded from the plantar muscles of the hind paw, with the active needle electrode (30-gauge) inserted between the fourth and fifth metatarsals, and the reference electrode inserted in the skin of the fifth digit. To elicit the H-reflex and study its rate sensitivity, the tibial nerve at the ankle was stimulated for $0.1 \mathrm{~ms}$ at $0.1,0.3,1,2,3$ and $5 \mathrm{~Hz}$ using the TECA Sapphire $4 \mathrm{ME}$ EMG unit. The cathode needle was inserted subcutaneously at the ankle, just above the heel, and the anode needle was inserted subcutaneously at the plantar surface of the heel. The intensity of the stimulus was adjusted to elicit the maximal consistent $\mathrm{H}$-wave amplitude. The recorded signal was passed to a differential amplifier and bandpass filtered at $0.1 \mathrm{~Hz}$ and $10 \mathrm{kHz}$. The analog signal was then sent to an A/D converter and the digital waveform (recorded at $30 \mathrm{kHz}$ ) and stored. Sixteen consecutive waveforms were collected at each frequency. The differences in amplitudes of $\mathrm{M}$ - and $\mathrm{H}$-waves as determined by the peak-to-peak values of each waveform were used to calculate the H-reflex depression. The investigator was blinded to the experimental groups during data recording and analyses.

\subsection{Autonomic Bladder Control Recovery}

Crede's maneuver was used to express the bladders of the injured rats. We used this technique to express the bladder three times a day until bladder function was restored. Each morning we counted how many rats in each diet regained bladder control before $7 \mathrm{dpi}$ and after $7 \mathrm{dpi}$. Bladder function is restored when the maximum amount of collected volume is $500 \mu \mathrm{L}$ or less for at least two consecutive days. 


\subsection{Immunohistochemistry Studies and Microscopy}

Spinal cord coronal sections were dried at room temperature for 10-15 min, washed with Phosphate Buffer Saline (PBS) for $5 \mathrm{~min}$, and post-fixed with $4 \%$ PFA for $10 \mathrm{~min}$. The sections were blocked with 20\% Bovine Serum Albumin (BSA) for $2 \mathrm{~h}$ at room temperature, and incubated at $4{ }^{\circ} \mathrm{C}$ in antibody solutions containing either mouse anti-Neuronal Nuclei (NeuN) monoclonal antibody (clone A60, 1:100; from Millipore, Billerica, MA, USA), mouse anti-adenomatous polyposis coli (APC)-7 monoclonal antibody (clone CC-1, 1:200; from Calbiochem, San Diego, CA, USA), and rabbit polyclonal anti-5HT antibody (1:500; from Abcam, Cambridge, MA, USA) to examine the immunoreactivity (IR) and cell numbers of neurons, mature oligodendrocytes, and IR of serotonin. On the next day, the sections were incubated with Alexa Fluor ${ }^{\circledR} 488$ or 594-conjugated donkey anti-mouse (1:500; from Invitrogen, Carlsbad, CA, USA). Control slides were incubated without primary antibodies to further confirm the specificity of the IR. The slides were examined with a BIOREVO BZ-9000 fluorescent microscope (Keyence, Itasca, IL, USA)

\subsection{Statistical Analyses}

Data are presented as mean +/- SEM. One-way analysis of variance (ANOVA), followed by Bonferroni post-hoc comparisons, was used to determine the effect of spinal cord injury and vitamin $\mathrm{E}$ supplementation on open-field locomotion scores, H-reflex depression, NeuN+ cell counts, APC + cell counts, and 5HT IR. Unpaired $t$-test was used to analyze the difference of APC + cell counts between uninjured and injured vitamin E groups. Fisher's Exact Test was used to determine the effect of vitamin $\mathrm{E}$ in bladder recovery during the first week post-SCI. Statistical analyses were performed using Prism 6 Software (GraphPad Software Inc., San Diego, CA, USA). Outliers were identified using the Grubbs' method, also known as ESD (extreme studentized deviate). Only one rat was excluded from the study after using these exclusion methods. Statistical differences were considered significant at $p<0.05$.

\section{Results}

\subsection{Dietary Vitamin E Improves Locomotor Recovery after SCI}

One week after behavioral habituation period, female Sprague-Dawley rats were provided ad libitum access to one of two diets: control diet or vitamin E-enriched diet (See Table 1 for detailed diet composition). The rats remained on their assigned diets for a total of 8 weeks before injury and 1-week post-SCI. Functional recovery was assessed during the first week after injury. At the end of the study, the spinal cords were harvested and tissues were used for immunohistochemical studies (Figure 1 summarizes the study timeline). The BBB locomotor grading scale was used to evaluate the effects of vitamin $\mathrm{E}$ pre-administration on the functional recovery of injured rats. A video recording of each subject's performance in the open field was obtained at 1 and 7 days post-injury (dpi). We found significant improvements in locomotor behavior in rats from dietary vitamin E prophylaxis group $(n=12)$ compared to rats fed with control diet at 7 dpi $(n=14)$ (Figure $2 \mathrm{~A})(\mathrm{F}(3,4190)=367.2, \mathrm{CTL}$ INJ, $n=14$ versus VIT E INJ, $\left.n=12^{* * *} p<0.001\right)$. Still images from representative rats fed control diets shows limited movement, dragging of hindlegs, and slight movement of hindlimb joints (Figure 2B) at 7 dpi. Interestingly, rats fed with the vitamin E enriched diet exhibited signs of intermediate locomotor recovery, as indicated by their ability to generate extensive movements of all three joints with dorsal-stepping patterns (Figure 2). 
Table 1. Detailed diet composition for Control and vitamin E-Enriched Diet.

\begin{tabular}{ccc}
\hline Ingredient & AIN-93G Control Diet (\%) & AIN-93G Vitamin E \\
\hline Soybean Oil & 7 & 7 \\
Vitamin E, IU kg & 0.0816 & 51 \\
Total Saturated Fat & $1.13 \mathrm{~g} / 100 \mathrm{~g}$ & $1.00 \mathrm{~g} / 100 \mathrm{~g}$ \\
Total Monosaturated Fat & $1.61 \mathrm{~g} / 100 \mathrm{~g}$ & $1.49 \mathrm{~g} / 100 \mathrm{~g}$ \\
Total Polysaturated Fat & $4.09 \mathrm{~g} / 100 \mathrm{~g}$ & $4.34 \mathrm{~g} / 100 \mathrm{~g}$ \\
Percentage kcal Carbohydrates & 64.7 & 60.5 \\
Percentages kcal Protein & 18.8 & 21.1 \\
Percentage kcal Fat & 16.5 & 18.4 \\
\hline
\end{tabular}

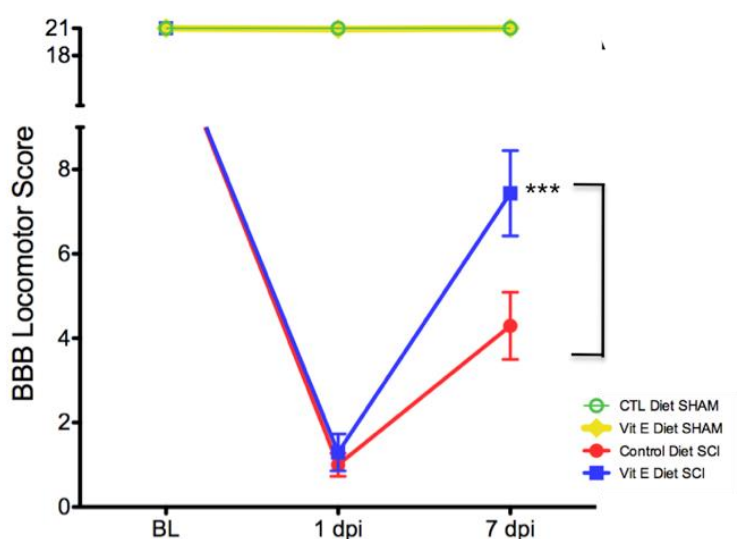

A

Days Post-Operation
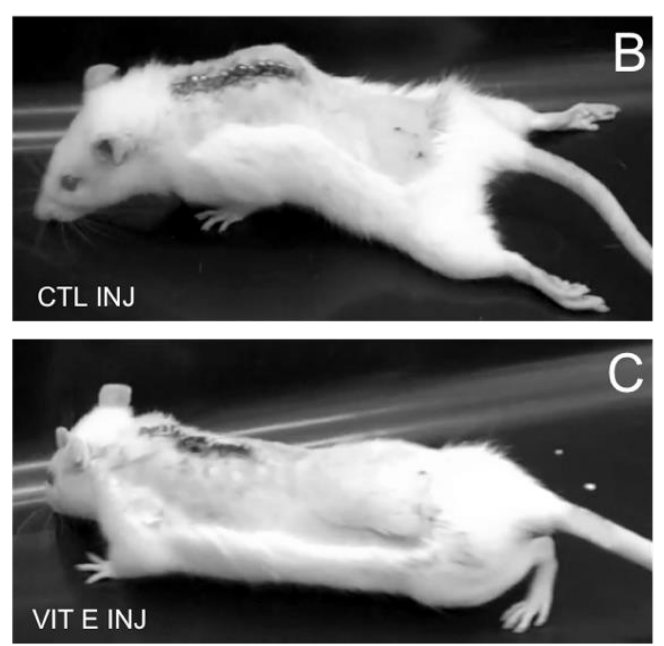

Figure 2. Beneficial effects of dietary vitamin E prophylaxis on the hindlimb neurological function of rats after a moderate injury, as assessed by the Basso-Beattie-Bresnahan (BBB) locomotor rating scale. (A) Effects of dietary vitamin E prophylaxis on locomotor function. Time (in days) following pretreatment and spinal cord compression (injury) is shown on the horizontal axis, BBB locomotor rating scores are shown on the vertical axis. Injured rats in the dietary vitamin E prophylaxis group had higher BBB scores of at least 7 when compared to controls. Open-field locomotion still images from control diets- (B) and dietary vitamin E prophylaxis rats (C) at 7 days post-injury (dpi). Mean dietary vitamin E prophylaxis scores revealed that most rats exhibited extensive movements of three joints with dorsal-stepping patterns at $7 \mathrm{dpi}$. Bonferroni test analysis was carried out to determine the statistically significant differences between diet treatments. Error bars represent means \pm standard error of the mean (CTL INJ versus VIT E INJ *** $p<0.001$; CTL INJ, $n=14$; VIT E INJ, $n=12$ ). CTL = control, VIT = vitamin, INJ = injury

\subsection{Dietary Vitamin E Prophylaxis Restores H-Reflex Depression at 7 dpi at $5 \mathrm{~Hz}$.}

Hyperreflexia and spasticity are common complications in SCI with limited availability for safe and effective treatment. A central mechanism in spasticity is hyperexcitability of the spinal stretch reflex. This reflex presents symptomatically as a velocity-dependent increase in tonic stretch reflexes and exaggerated tendon jerks, resulting in functional deficits, pain, and musculoskeletal deformities. Given that the Hoffmann's reflex (H-reflex) can be evoked in rats, we chose to study the efficacy of our dietary intervention to restore this reflex. As expected, we found reduced H-reflex depression as the stimulation frequency was increased in SCI rats. Notably, the rats that consumed the vitamin E-supplemented diet showed improved H-reflex depression, suggesting less SCI-induced hyperreflexia. Sham-operated rats exhibited normal H-reflex depression in both dietary groups (control diet and vitamin E prophylaxis) (Figure 3A). 
Vertical bars in Figure 3B represent the size of the difference between the M-wave and the H-wave at $5 \mathrm{~Hz}$ compared to low frequency stimulation $(0.1 \mathrm{~Hz})$. A lower vertical bar on the $y$-axis indicates a bigger difference between the $\mathrm{M}$-wave and $\mathrm{H}$-wave (the latter being smaller), thus showing more H-reflex depression. A higher vertical bar on the $y$-axis value indicates a smaller difference between the $\mathrm{M}$-wave and the $\mathrm{H}$-wave at $5 \mathrm{~Hz}$ compared to $0.1 \mathrm{~Hz}$ thus less $\mathrm{H}$-reflex depression.
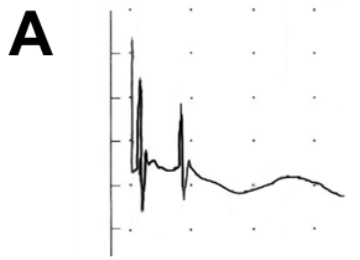

CTL SHAM

$0.1 \mathrm{~Hz}$

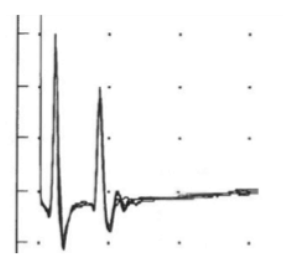

VIT E SHAM

$0.1 \mathrm{~Hz}$

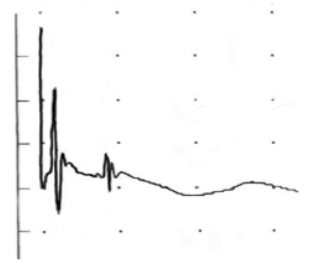

$5 \mathrm{~Hz}$

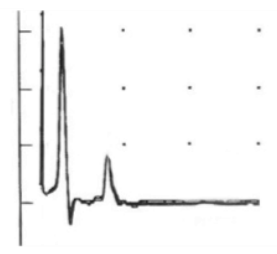

$5 \mathrm{~Hz}$

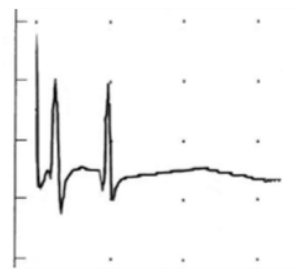

CTL INJ

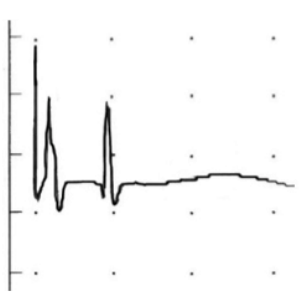

$5 \mathrm{~Hz}$

$0.1 \mathrm{~Hz}$

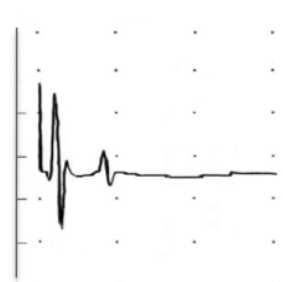

VIT E INJ

$0.1 \mathrm{~Hz}$

$5 \mathrm{~Hz}$

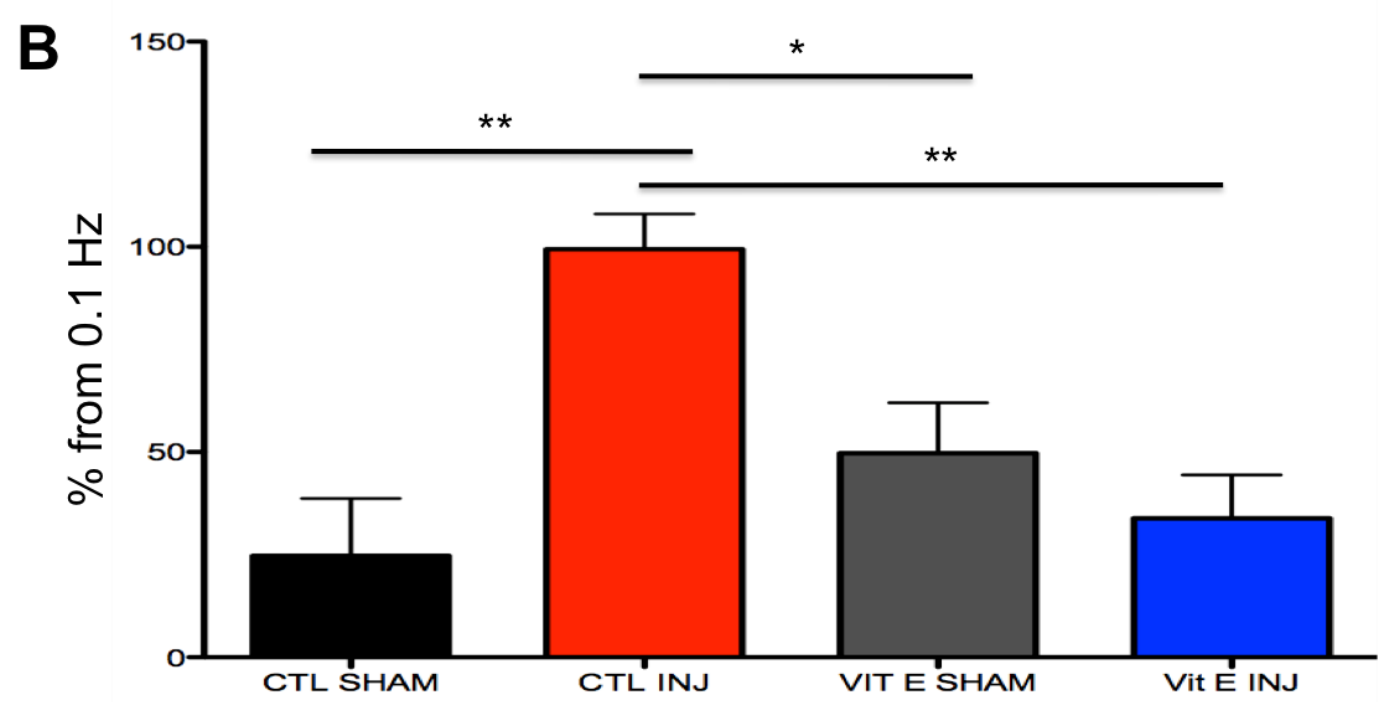

Figure 3. Dietary vitamin E prophylaxis restores H-reflex depression at $7 \mathrm{dpi}$ at $5 \mathrm{~Hz}$. Increased amplitudes on the y axis at $5 \mathrm{~Hz}$ indicate less $\mathrm{H}$-reflex rate depression, whereas decreased amplitudes indicate more rate depression. The H-reflex depression after increased frequency (i.e., $5 \mathrm{~Hz}$ ) was abnormal in rats on a control diet after SCI but it was restored in rats on dietary vitamin E prophylaxis after SCI at $7 \mathrm{dpi}$ (A). Higher percent changes from $0.1 \mathrm{~Hz}$ at $5 \mathrm{~Hz}$ indicate abnormal H-reflex rate depression after SCI in rats on a control diet but not in rats on dietary vitamin E prophylaxis at $7 \mathrm{dpi}$ where there was a lower percent change from $.1 \mathrm{~Hz}(\mathbf{B}) .\left({ }^{* *} p<0.01\right.$ CTL SHAM vs. CTL INJ and CTL INJ vs. VIT E INJ and * $p<0.05$ VIT E SHAM vs. CTL INJ; CTL SHAM $n=6$, CTL INJ $n=6$, VIT E SHAM $n=6$, VIT E INJ $n=7$ )

In uninjured control rats and uninjured rats that received and vitamin $\mathrm{E}$ diet, the H-wave steadily decreased with increasing stimulus frequency with the maximum frequency being $5 \mathrm{~Hz}$. However, in 
injured rats that received a control diet before SCI, the H-wave depression was inhibited showing how the H-reflex was less sensitive to increased stimulus frequency at $5 \mathrm{~Hz}$. As shown in Figure 3, injured rats that received a vitamin E diet before SCI showed a decrease in H-wave depression similarly to uninjured control rats and uninjured vitamin $\mathrm{E}$ rats. This finding is indicated by a lower H-wave amplitude at $5 \mathrm{~Hz}$ compared to injured rats from a control diet (Figure 3) $(\mathrm{F}(3,20,287)=8.231$, $\left({ }^{* *} p<0.01\right.$ CTL SHAM vs. CTL INJ and ${ }^{* *} p<0.01$ CTL INJ vs. VIT E INJ and ${ }^{*} p<0.05$ VIT E SHAM vs. CTL INJ; CTL SHAM $n=6$, CTL INJ $n=6$, VIT E SHAM $n=6$, VIT E INJ $n=7$ ). In summary, H-reflex depression became abnormal after SCI only in injured rats that received a control diet before SCI but not in injured rats that received a vitamin E diet before SCI.

\subsection{Beneficial Effects of Dietary Vitamin E Prophylaxis on Autonomic Function after Contusion Injury}

SCI results in a period of distinctive bladder dysfunction [56-63]. Manual collection and quantification of the residual urine volume was done to assess whether dietary vitamin E prophylaxis show efficacy in accelerating autonomic bladder recovery (Figure 4). For each rat, the number of days needed to attain full autonomic recovery was defined as residual volume of $0.5 \mathrm{~mL}$ or less for 2 or more consecutive days, as previously reported by our group. We found that the rats that consumed the vitamin E-enriched diet restored bladder function faster relative to controls. (Fisher's Test analysis of contingency tables * $p<0.05$ CTL INJ $n=15$, VIT E INJ $n=13$ ).

\begin{tabular}{|c|c|c|}
\hline \multicolumn{3}{|c|}{ Bladder Recovery } \\
\hline & $<7 \mathbf{d p i}$ & $>\mathbf{7 d p i}$ \\
\hline Control Injury & $33 \%, \mathrm{n}=5$ & $67 \%, \mathrm{n}=10$ \\
\hline Vitamin E Injury & $69 \%, \mathrm{n}=9$ & $31 \%, \mathrm{n}=4$ \\
\hline
\end{tabular}

Figure 4. Beneficial effects of dietary vitamin E prophylaxis on autonomic function after SCI. Residual urine volumes $(\mathrm{mL})$ differed significantly between control and dietary vitamin E prophylaxis pre-treated groups at $7 \mathrm{dpi}$. For each rat, the number of days needed to attain full autonomic recovery was defined as residual volume of $0.5 \mathrm{~mL}$ for 2 or more consecutive days. Dietary vitamin E prophylaxis resulted in fewer days $(<7)$ to attain full bladder recovery $(* p<0.05$ CTL INJ vs. VIT E INJ)

\subsection{Dietary Vitamin E Does Not Preserve Neurons at 1 Week after Spinal Cord Injury (SCI)}

To determine the number of motor neurons in the ventral gray matter of the spinal cord, immunohistochemical analyses were performed during the first week following SCI. This represents a critical period in apoptotic cell death in SCI models [26-30]. Consistent with previous findings, we found a significant decrease in the number of neuronal nuclei positive $(\mathrm{NeuN}+)$ cells in the ventral gray matter of injured rats when compared to uninjured sham rats at 1-week post-SCI. Interestingly, the dietary intervention did not result in increased NeuN+ cells after SCI. Representative images from sections labeled anti-NeuN (Figure 5A) did not show significant differences in motor neuron cell counts when comparing vitamin E-fed rats with controls at $7 \mathrm{dpi}(p>0.05)(\mathrm{F}(3,13,256)=13.19$, ${ }^{* *} p<0.01$, CTL SHAM, $n=6$ vs. CTL INJ, $n=6$; ${ }^{* *} p<0.001$ CTL SHAM, $n=6$ vs. VIT E INJ, $n=7$; $p>0.05$, CTL INJ, $n=6$ vs. VIT E INJ, $n=7)$. 


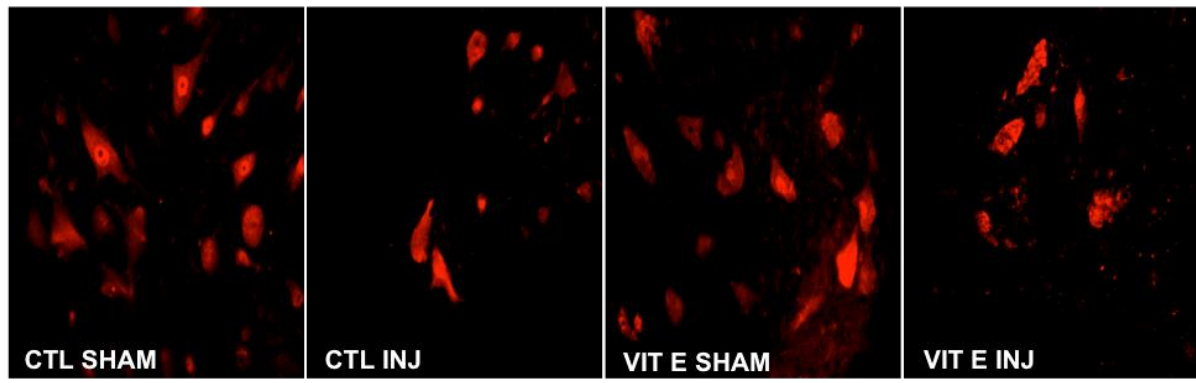

A

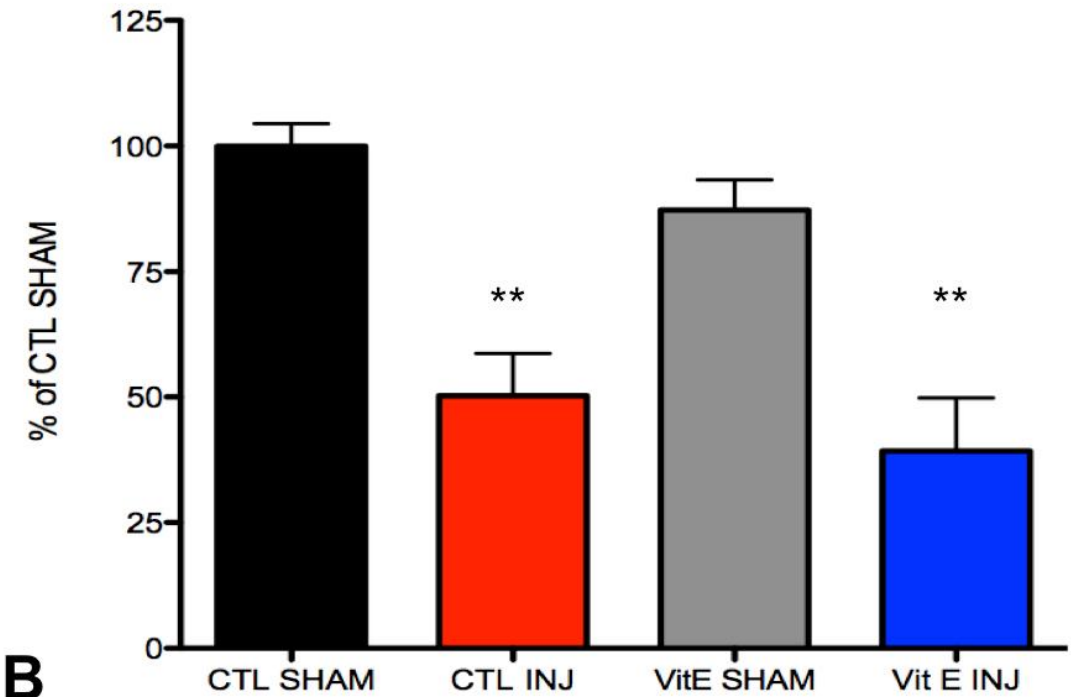

Figure 5. Vitamin E does not preserve neurons at 1 week after SCI. (A) Expression of neuronal markers was quantified in the ventral gray matter (VGM). (B) Manual quantification of cell numbers and normalization to controls shams revealed decreased numbers of NeuN+ cells in the VGM in injured control rats and injured vitamin $\mathrm{E}$ fed rats. The number of NeuN+ cells in the ventral gray matter of the spinal cord from injured control rats was not significantly different from injured vitamin $\mathrm{E}$ fed rats. Bonferroni test analysis was carried out to determine the statistically significant differences between diet treatments. Error bars represent mean \pm standard error of the mean (** $p<0.01$, CTL SHAM, $n=6$ vs. CTL INJ, $n=6$; CTL SHAM, $n=6$ vs. VIT E INJ, $n=7 ; p>0.05$, CTL INJ, $n=6$ vs. VIT E INJ, $n=7)$.

\subsection{Dietary Vitamin E Preserves Oligodendrocytes Following SCI}

We performed immunohistological analyses to determine the number of oligodendrocytes in the white matter at $7 \mathrm{dpi}$. Oligodendrocytes were immunodetected using the anti-adenomatosis polyposis coli (APC) antibody. Our results confirmed previous studies showing a significant decrease in the number of oligodendrocytes at one-week post-SCI. Representative images from injured sections labeled with the APC antibody show increased number of APC positive cells in the spinal cord of rats fed the vitamin E diet when compared to controls. Interestingly, the analysis showed that there was an increased number of APC positive cells in the spinal cord of injured rats that were fed the vitamin E diet compared to control injured rats. There was no significant difference between APC positive cells between uninjured rats in the control diet and vitamin $\mathrm{E}$ diet. $(p<0.05)$ (Figure 6) $(\mathrm{F}(3,26,619)=18.05$, ${ }^{* * *} p<0.001$, CTL SHAM, $n=6$ vs. CTL INJ, $\left.n=6\right)$; ${ }^{* *} p<0.01$, VIT E INJ, $n=7$ vs. CTL INJ, $n=6$ ); $p>0.05$, CTL SHAM, $n=6$ vs. VIT E SHAM, $n=6$ ). Further statistical analysis showed that there was a significant difference in APC positive cells between uninjured rats in the vitamin E diet and injured vitamin $\mathrm{E}$ diet when they were analyzed using an unpaired $t$-test $(p=0.0059)$. 


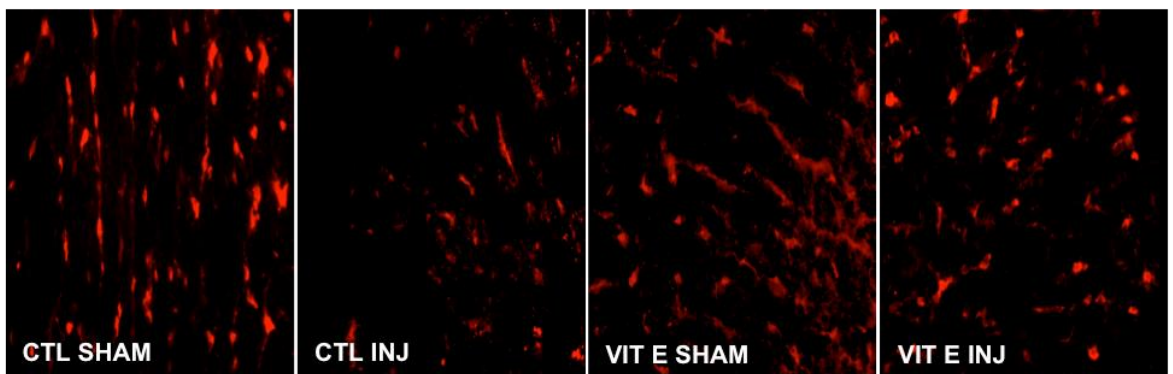

A

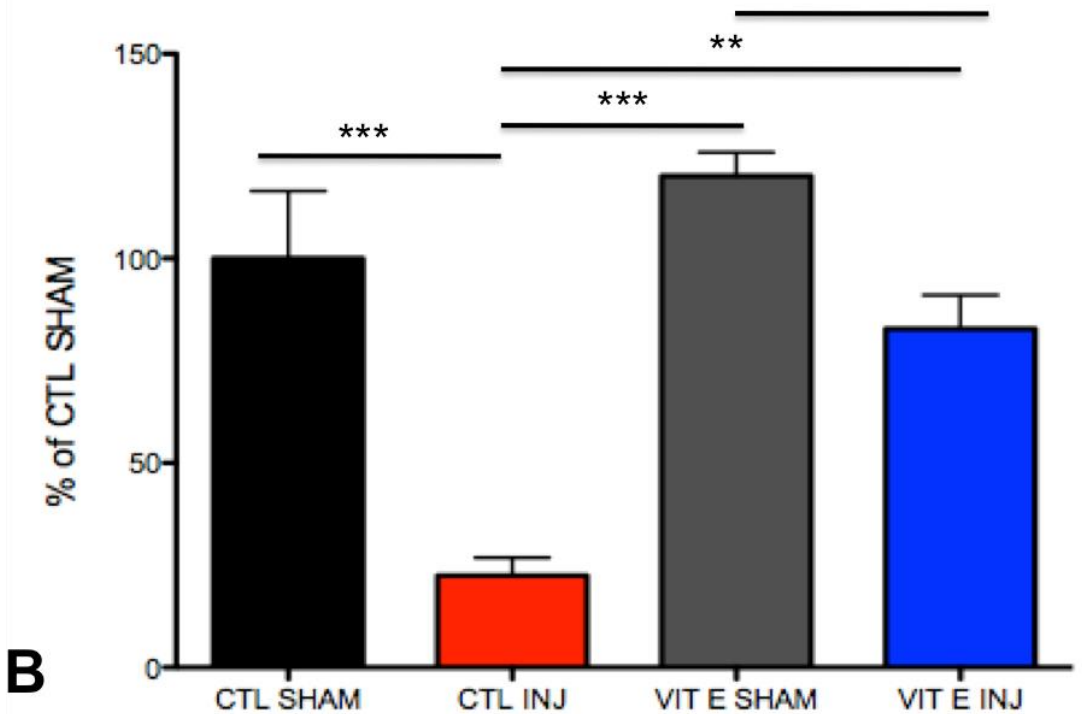

Figure 6. Vitamin E preserves oligodendrocytes at 1 week after spinal cord injury. (A)Expression of oligodendrocyte markers was quantified in the white matter of the spinal cord. (B) Manual quantification of cell numbers and normalization to control shams revealed decreased numbers of $\mathrm{APC}+$ in the white matter of injured control rats, but not in injured vitamin $\mathrm{E}$ fed rats. There was a statistically significant increase of APC + cells in vitamin E fed rats compared to injured control rats. Bonferroni test analysis was carried out to determine the statistically significant differences between diets. There was a significant difference in APC positive cells between uninjured rats in the vitamin E-enriched diet and injured vitamin E-enriched diet when they were analyzed using an unpaired $t$-test $(+p=0.0059)$. Error bars represent means \pm standard error of the mean ${ }^{* * *} p<0.0001$, CTL SHAM, $n=6$ vs. CTL INJ, $n=6$ and VIT E SHAM, $n=5$ vs. CTL INJ, $n=6 ; p>0.05$ CTL SHAM, $n=6$ vs. VIT E INJ, $n=7$ and CTL SHAM, $n=6$ vs. VIT E SHAM, $n=5$; ${ }^{* *} p<0.01$, VIT E INJ, $n=7$ vs. CTL INJ, $\left.n=6\right)$.

\subsection{Dietary Vitamin E Upregulates Serotonin Immunoreactivity Following SCI}

Previous studies have shown decreased serotonin levels after moderate-contusive SCI [64]. Serotonin inhibits afferent transmission and spinal reflexes and plays crucial roles in functional recovery after SCI [65-71]. Serotonergic signaling is a key mechanism underlying neuronal hyperexcitability after SCI, which has been demonstrated to underlie the pathogenesis of spasticity after SCI [72-76]. Thus, we postulated that vitamin E beneficial effects observed would be consistent with the modulation of the levels of this neurotransmitter. As hypothesized, we found a significant increase in the levels of serotonin in rats fed the vitamin E-enriched diet compared to the control diet in uninjured $\left({ }^{*} p<0.05\right.$, CTL SHAM, $n=5$ vs. VIT E SHAM, $n=5)$ and injured rats $\left({ }^{*} p<0.05\right.$, CTL INJ, $n=5$ vs. VIT E INJ, $n=5$ ) (Figure 7B). Interestingly, we found no significant difference between sham and injured rats $(p>0.05, p=$ at least 5 rats $)$. 

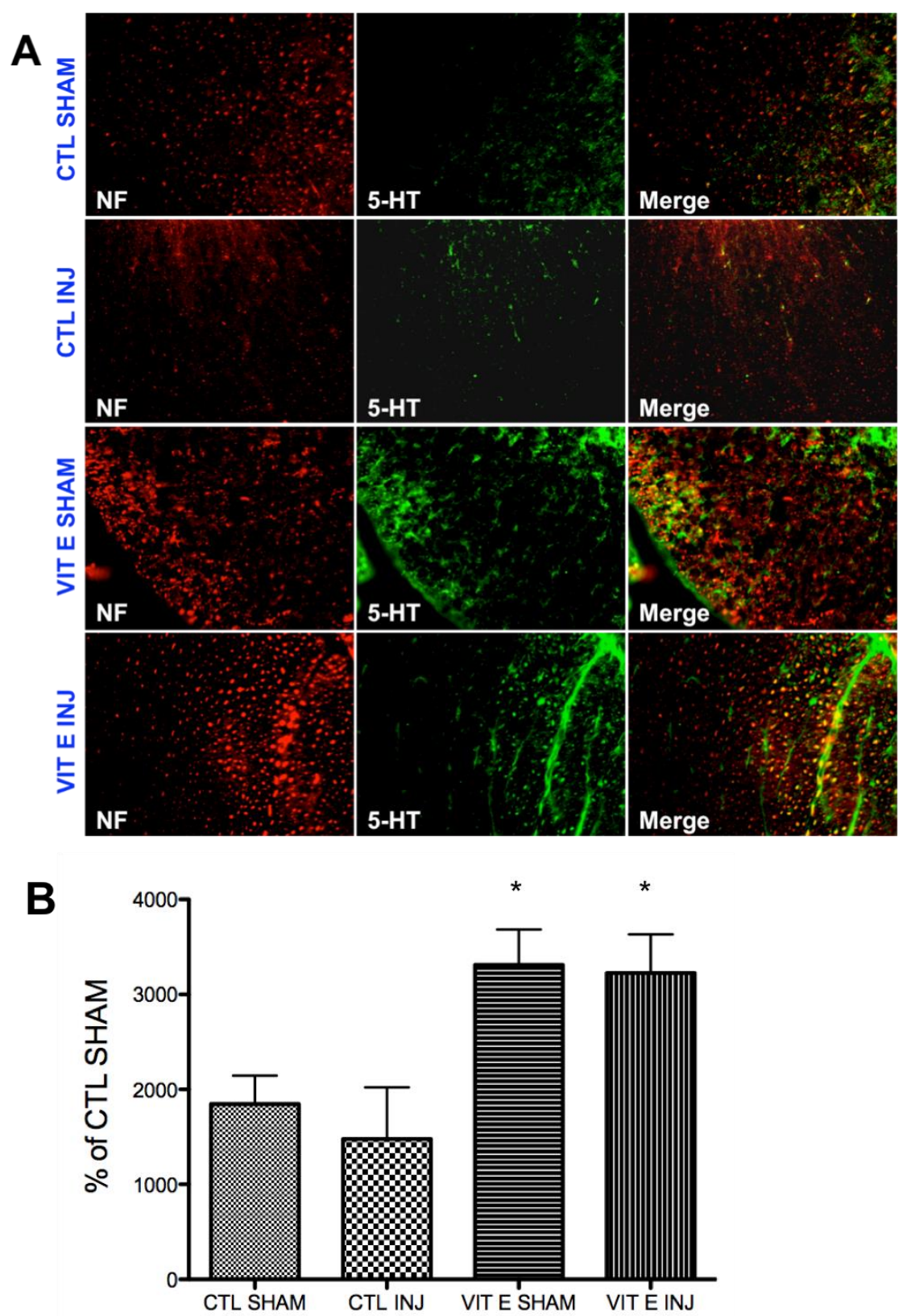

Figure 7. Vitamin E prophylaxis upregulate serotonin immunoreactivity in the white matter at $7 \mathrm{dpi}$. Serotonin IR was quantified in the white matter at $7 \mathrm{dpi}$ in all four groups (Figure 7A). There was a diet-dependent upregulation of 5-HT-IR in uninjured rats ( ${ }^{*} p<0.05$, CTL SHAM, $n=5$ vs. VIT E SHAM, $n=5)$ and injured rats ( $p<0.05$, CTL INJ, $n=5$ vs. VIT E INJ, $n=5$ ) (Figure 7B). There was no difference between uninjured and injured rats in the control diet $(p>0.05$, CTL SHAM, $n=5$ vs. CTL INJ, $n=5)$ and between uninjured and injured rats in the vitamin E diet ( $p>0.05$, VIT E SHAM, $n=5$ vs. VIT E INJ, $n=5)$. 5-HT (5-hydroxytryptamine), NF (neurofilament).

\section{Discussion}

The present study reports novel findings showing that a two-month chronic dietary supplementation with vitamin E (alpha-tocopherol) improves recovery during the acute phase of SCI and identify potential targets. The significant prophylactic effects of vitamin E supplementation included improved functional locomotor outcomes, accelerated bladder recovery measured in urinary retention time, and reduced hyperreflexia after SCI. Further, the dietary intervention increased numbers 
of oligodendrocytes and increased supraspinal serotonin IR, indicating potential targets underlying the restorative potential of vitamin E in SCI.

Spinal cord injury has a devastating effect on affected individuals. Patients experience serious secondary complications such as urinary retention, a sign of autonomic bladder dysfunction, that has serious practical physiological and psychological consequences $[77,78]$. Thus, the search of alternative complementary interventions with the potential to lessen the effect of this condition is needed. Although there have been several studies considering the effects of vitamin E during spinal cord injury, little progress has been made in developing appropriate evidence-based complementary therapies. Questions needed to be address for further assessment include appropriate dosage, timing of administration and proper use of dietary prophylaxis. Also, while several studies have shown the effects of vitamin $\mathrm{E}$ on improvement locomotion and other parameters, these effects on locomotion has not been quantified using the BBB scores and it is unknown whether this complementary treatment is beneficial in addressing urinary retention time, or the H-reflex. To properly evaluate a potential vitamin $E$ effect on these parameters it is important to ensure that the animal is exposed to the proper levels of vitamin E. The current study uses dietary prophylaxis with vitamin E by exposing the animals to a chronic dietary intervention for two months before the animal were subject to the traumatic contusion injury on the cord. A chronic dietary intervention was deemed to be a better approach to avoid potential hurdles associated with vitamin E stability. This approach allowed us to assess with confidence key functional outcomes and determine whether vitamin $E$ had a significant impact. We also proceeded to assess selective functional parameters and quantifying vitamin $E$ effects on locomotion using for the first time the BBB scores.

The well documented antioxidant actions of vitamin E would be beneficial in physiological process that, while affected by the injury, still have functional connections. In this context, we evaluate whether bladder dysfunction was a good target for this treatment. Current interventions used to reduce bladder dysfunction after SCI include cholinergic muscarinic receptor antagonists [79-85], chemical blockade of C-fiber afferent neurotransmission with capsaicin or resiniferatoxin [86-92] and alpha1acetylcholine receptor (AR) receptor antagonists [93-99]. Additional interventions include suppression of motorneuron or interneuron excitation in the spinal cord by glycine, GABA agonists, and baclofan is being used to treat dysfunctional contraction of the external urethral sphincter [100-106]. Botulin toxin, a presynaptic neuromuscular blocker, is now FDA-approved to treat bladder hyperreflexia by inducing reversible muscle weakness [107-112]. Various studies support the use of antioxidant therapy to address bladder function following SCI. For instance, treatment with quercetin was shown to improve bladder contractility, while decreasing reactive oxygen species, plasma cytokines, and caspase 3, and prevented depletion of free radical scavengers after SCI in rats [113]. Additional treatment with antioxidant cranberry extract supplements for at least 6 months showed a decrease in urinary tract infections [114]. These approaches to address bladder recovery following SCI suggest that complementary therapies that can improve nerve conduction may be useful as part of comprehensive treatment. In this context, vitamin E could specifically decrease urinary retention through the improvement of nerve conduction. For instance, spinal cord evoked potentials after injury showed greater recovery of both amplitude and latency in a vitamin E supplemented group compared to control $[44,48]$ ). Also, in the present study we found that vitamin E supplementation significantly inhibits the $\mathrm{H}$-reflex depression. These findings are consistent with a role of vitamin $\mathrm{E}$ in enhancing nerve conductivity in the injured cord which is may also explain the significant increase in the BBB locomotion scores seen in these animals fed with the enriched vitamin $\mathrm{E}$ diet reported here. These data expand previous work showing vitamin E improving locomotion when administered in a prophylactic manner $[43,44,48]$ or after injury $[45,46]$. When compared to vitamin $C$ supplementation after injury, vitamin E was shown to be more effective for locomotion recovery [46]. Proven actions of vitamin E in reducing lipid peroxidation products such as thiobarbituric acid reactive substances $[44,48]$ and malondialdehyde [47] may be responsible at least in part for these effects [36]. Further, vitamin E improves recovery by decreasing ischemia [42] and downregulating arachidonate and prostanoids [41]. 
The improved outcomes exhibited by the rats that consumed the vitamin E-enriched diet were associated with an increased preservation of oligodendrocytes of the injured cord. Interestingly, this increase of oligodendrocytes survival was not accompany with an increased survival of neurons. This finding is consistent with reports showing the high vulnerability of oligodendrocytes to oxidative stress. For instance, oligodendrocytes and pre-oligodendrocytes have been shown to be highly sensitive to abnormal high levels of intracellular free radicals that follow cysteine deprivation and treatment with vitamin $\mathrm{E}$ and other ROS scavengers (ascorbate, idebenone, and N-tert-butyl-alpha-phenylnitrone) promote their survival $[115,116]$. Vitamin E also protects murine oligodendrocytes in culture from ROS generation and apoptosis caused by cytotoxic oxysterols [117-119], and from lipid peroxidation in combination with ascorbate acid [120]. Although this was not directly addressed in the present study, a significant increase in oligodendrocytes in the rats that consumed the vitamin E diet may be implicated in the improvement seen on H-reflex depression, bladder reflex recovery, and locomotion in these rats because of myelin and axonal preservation [25,121-126]. Therefore, vitamin E may be able to exert its beneficial effects in the event of spinal cord injury even in the absence of neuronal preservation due to increased survival of oligodendrocytes. Future clinical study may be necessary to assess the value of a similar strategy to treat bladder dysfunction and improve nerve conductivity following SCI.

Our results showing a significant upregulation in serotonin levels in rats fed a vitamin E prophylactic diet further strengthens vitamin E as a potential therapeutic agent for SCI complications. This is supported by several studies showing an improved voiding efficiency after SCI following increased catecholaminergic and serotonergic axonal growth [127-130]. This is consistent with findings showing a direct correlation between low serotonin and abnormal H-reflex depression [64]. Serotonin depletion has also been found to positively correlate with the degree of paralysis and disease severity in rat model for multiple sclerosis [131,132]. In models of SCI regeneration of spinal serotonergic neurons is associated with functional recovery $[133,134]$.

In summary, we propose increased survival of oligodendrocytes and upregulation of serotonin levels as potential mechanisms through which dietary vitamin E prophylaxis improves locomotion, $\mathrm{H}$ reflex depression, and bladder recovery in the context of SCI.

The findings reported herein are consistent with previous studies from our lab showing that administration of antioxidants such as omega-3 fatty acids stimulate recovery following contusion injury to the spinal cord [38-40]. To date, several studies have shown the beneficial effects of antioxidants to restore function after trauma. However, studies investigating the effects of dietary vitamin $\mathrm{E}$ in neural repair are limited. Our findings suggest the potential of this nutritional-based intervention to ameliorate functional impairments and cell survival following SCI. Furthermore, our study supports the importance of nutrition to ameliorate the augmented state of cellular oxidative stress observed during SCI.

\section{Conclusions}

In conclusion our study reports provides evidence that a two-month chronic dietary supplementation with vitamin E (alpha-tocopherol) aids in the functional recovery of SCI during the acute phase. Specifically, vitamin E seemed to have a prophylactic effect resulting in improved locomotor outcomes, accelerated bladder recovery measured in urinary retention time, and reduced hyperreflexia. Our data indicates that increased survival of oligodendrocytes and increased supraspinal serotonin IR are potential targets for the underlying mechanisms of vitamin $\mathrm{E}$ and its prophylactic effects in the acute phase of SCI. Further studies need to be done to investigate the effects of vitamin E in the chronic phase after SCI.

Acknowledgments: The authors are indebted to Alfonso Duran and other members in De Leon lab members for helpful feedbacks and help with animal care. Research reported in this publication was supported in part NIH awards R25GM060507 and P20MD006988 to MDL. The content is solely the responsibility of the authors and does not necessarily represent the official views of the National Institutes of Health. 
Author Contributions: K.C., J.D.F., and M.D.L. conceived and designed the experiments. K.C. performed the behavioral studies along with M.S.-I. K.C. performed the immunihistochemical studies along with G.G.C. and J.C.-B. K.C. analyzed the data and wrote the paper. J.D.F. and M.D.L. edited the paper.

Conflicts of Interest: The authors declare no conflict of interest.

\section{References}

1. Dallmeijer, A.J.; van der Woude, L.H.; van Kamp, G.J.; Hollander, A.P. Changes in lipid, lipoprotein and apolipoprotein profiles in persons with spinal cord injuries during the first 2 years post-injury. Spinal Cord 1999, 37, 96-102. [CrossRef] [PubMed]

2. Demediuk, P.; Saunders, R.D.; Anderson, D.K.; Means, E.D.; Horrocks, L.A. Membrane lipid changes in laminectomized and traumatized cat spinal cord. Proc. Natl. Acad. Sci. USA 1985, 82, 7071-7075. [CrossRef] [PubMed]

3. Demediuk, P.; Saunders, R.D.; Anderson, D.K.; Means, E.D.; Horrocks, L.A. Early membrane lipid changes in laminectomized and traumatized cat spinal cord. Neurochem. Pathol. 1987, 7, 79-89. [CrossRef] [PubMed]

4. Demediuk, P.; Saunders, R.D.; Clendenon, N.R.; Means, E.D.; Anderson, D.K.; Horrocks, L.A. Changes in lipid metabolism in traumatized spinal cord. Prog. Brain Res. 1985, 63, 211-226. [PubMed]

5. Bauman, W.A.; Spungen, A.M. Metabolic changes in persons after spinal cord injury. Phys. Med. Rehabil. Clin. N. Am. 2000, 11, 109-140. [PubMed]

6. Kearns, P.J.; Thompson, J.D.; Werner, P.C.; Pipp, T.L.; Wilmot, C.B. Nutritional and metabolic response to acute spinal-cord injury. JPEN J. Parenter. Enteral Nutr. 1992, 16, 11-15. [CrossRef] [PubMed]

7. Murai, H.; Itoh, C.; Wagai, N.; Nakamura, T.; Yamaura, A.; Makino, H. Ocal spinal cord glucose utilization and extracellular potassium activity changes after spinal cord injury in rats. No To Shinkei 1991, 43, 337-342. [PubMed]

8. Vink, R.; Noble, L.J.; Knoblach, S.M.; Bendall, M.R.; Faden, A.I. Metabolic changes in rabbit spinal cord after trauma: Magnetic resonance spectroscopy studies. Ann. Neurol. 1989, 25, 26-31. [CrossRef] [PubMed]

9. Schwartzman, R.J.; Eidelberg, E.; Alexander, G.M.; Yu, J. Regional metabolic changes in the spinal cord related to spinal shock and later hyperreflexia in monkeys. Ann. Neurol. 1983, 14, 33-37. [CrossRef] [PubMed]

10. Liu, D.; Ling, X.; Wen, J.; Liu, J. The role of reactive nitrogen species in secondary spinal cord injury: Formation of nitric oxide, peroxynitrite, and nitrated protein. J. Neurochem. 2000, 75, 2144-2154. [CrossRef] [PubMed]

11. David, S.; Kroner, A. Repertoire of microglial and macrophage responses after spinal cord injury. Nat. Rev. Neurosci. 2011, 12, 388-399. [CrossRef] [PubMed]

12. Hulsebosch, C.E. Recent advances in pathophysiology and treatment of spinal cord injury. Adv. Physiol Educ 2002, 26, 238-255. [CrossRef] [PubMed]

13. Trivedi, A.; Olivas, A.D.; Noble-Haeusslein, L.J. Inflammation and Spinal Cord Injury: Infiltrating Leukocytes as Determinants of Injury and Repair Processes. Clin. Neurosci. Res. 2006, 6, 283-292. [CrossRef] [PubMed]

14. Donnelly, D.J.; Popovich, P.G. Inflammation and its role in neuroprotection, axonal regeneration and functional recovery after spinal cord injury. Exp. Neurol. 2008, 209, 378-388. [CrossRef] [PubMed]

15. Popovich, P.G.; Wei, P.; Stokes, B.T. Cellular inflammatory response after spinal cord injury in Sprague-Dawley and Lewis rats. J. Comp. Neurol. 1997, 377, 443-464. [CrossRef]

16. Bartholdi, D.; Schwab, M.E. Expression of pro-inflammatory cytokine and chemokine mRNA upon experimental spinal cord injury in mouse: An in situ hybridization study. Eur J. Neurosci. 1997, 9, 1422-1438. [CrossRef] [PubMed]

17. Schwab, J.M.; Brechtel, K.; Nguyen, T.D.; Schluesener, H.J. Persistent accumulation of cyclooxygenase-1 (COX-1) expressing microglia/macrophages and upregulation by endothelium following spinal cord injury. J. Neuroimmunol. 2000, 111, 122-130. [CrossRef]

18. Resnick, D.K.; Graham, S.H.; Dixon, C.E.; Marion, D.W. Role of cyclooxygenase 2 in acute spinal cord injury. J. Neurotrauma 1998, 15, 1005-1013. [CrossRef] [PubMed]

19. Yan, P.; Li, Q.; Kim, G.M.; Xu, J.; Hsu, C.Y.; Xu, X.M. Cellular localization of tumor necrosis factor-alpha following acute spinal cord injury in adult rats. J. Neurotrauma 2001, 18, 563-568. [CrossRef] [PubMed] 
20. Blight, A.R. Macrophages and inflammatory damage in spinal cord injury. J. Neurotrauma 1992, 9, S83-S91. [PubMed]

21. Schwab, M.E.; Bartholdi, D. Degeneration and regeneration of axons in the lesioned spinal cord. Physiol. Rev. 1996, 76, 319-370. [CrossRef] [PubMed]

22. Guest, J.D.; Hiester, E.D.; Bunge, R.P. Demyelination and Schwann cell responses adjacent to injury epicenter cavities following chronic human spinal cord injury. Exp. Neurol. 2005, 192, 384-393. [CrossRef] [PubMed]

23. Bunge, R.P.; Puckett, W.R.; Becerra, J.L.; Marcillo, A.; Quencer, R.M. Observations on the pathology of human spinal cord injury. A review and classification of 22 new cases with details from a case of chronic cord compression with extensive focal demyelination. Adv. Neurol. 1993, 59, 75-89. [PubMed]

24. Bunge, R.P.; Puckett, W.R.; Hiester, E.D. Observations on the pathology of several types of human spinal cord injury, with emphasis on the astrocyte response to penetrating injuries. Adv. Neurol. 1997, 72, 305-315. [PubMed]

25. Totoiu, M.O.; Keirstead, H.S. Spinal cord injury is accompanied by chronic progressive demyelination. J. Comp. Neurol. 2005, 486, 373-383. [CrossRef] [PubMed]

26. Crowe, M.J.; Bresnahan, J.C.; Shuman, S.L.; Masters, J.N.; Beattie, M.S. Apoptosis and delayed degeneration after spinal cord injury in rats and monkeys. Nat. Med. 1997, 3, 73-76. [CrossRef] [PubMed]

27. Eldadah, B.A.; Faden, A.I. Caspase pathways, neuronal apoptosis, and CNS injury. J. Neurotrauma 2000, 17, 811-829. [CrossRef] [PubMed]

28. Emery, E.; Aldana, P.; Bunge, M.B.; Puckett, W.; Srinivasan, A.; Keane, R.W.; Bethea, J.; Levi, A.D. Apoptosis after traumatic human spinal cord injury. J. Neurosurg. 1998, 89, 911-920. [CrossRef] [PubMed]

29. Liu, X.Z.; Xu, X.M.; Hu, R.; Du, C.; Zhang, S.X.; McDonald, J.W.; Dong, H.X.; Wu, Y.J.; Fan, G.S.; Jacquin, M.F.; et al. Neuronal and glial apoptosis after traumatic spinal cord injury. J. Neurosci. 1997, 17, 5395-5406. [PubMed]

30. Beattie, M.S.; Farooqui, A.A.; Bresnahan, J.C. Review of current evidence for apoptosis after spinal cord injury. J. Neurotrauma 2000, 17, 915-925. [CrossRef] [PubMed]

31. Lu, J.; Ashwell, K.W.; Waite, P. Advances in secondary spinal cord injury: Role of apoptosis. Spine 2000, 25, 1859-1866. [CrossRef] [PubMed]

32. Abe, Y.; Yamamoto, T.; Sugiyama, Y.; Watanabe, T.; Saito, N.; Kayama, H.; Kumagai, T. Apoptotic cells associated with Wallerian degeneration after experimental spinal cord injury: A possible mechanism of oligodendroglial death. J. Neurotrauma 1999, 16, 945-952. [CrossRef] [PubMed]

33. Norenberg, M.D.; Smith, J.; Marcillo, A. The pathology of human spinal cord injury: Defining the problems. J. Neurotrauma 2004, 21, 429-440. [CrossRef] [PubMed]

34. Rowland, J.W.; Hawryluk, G.W.; Kwon, B.; Fehlings, M.G. Current status of acute spinal cord injury pathophysiology and emerging therapies: Promise on the horizon. Neurosurg. Focus 2008, 25, E2. [CrossRef] [PubMed]

35. Xiong, Y.; Rabchevsky, A.G.; Hall, E.D. Role of peroxynitrite in secondary oxidative damage after spinal cord injury. J. Neurochem. 2007, 100, 639-649. [CrossRef] [PubMed]

36. Bastani, N.E.; Kostovski, E.; Sakhi, A.K.; Karlsen, A.; Carlsen, M.H.; Hjeltnes, N.; Blomhoff, R.; Iversen, P.O. Reduced antioxidant defense and increased oxidative stress in spinal cord injured patients. Arch. Phys. Med. Rehabil. 2012, 93, 2223-2228. [CrossRef] [PubMed]

37. Hillard, V.H.; Peng, H.; Zhang, Y.; Das, K.; Murali, R.; Etlinger, J.D.; Zeman, R.J. Tempol, a nitroxide antioxidant, improves locomotor and histological outcomes after spinal cord contusion in rats. J. Neurotrauma 2004, 21, 1405-1414. [CrossRef] [PubMed]

38. Figueroa, J.D.; Cordero, K.; Baldeosingh, K.; Torrado, A.I.; Walker, R.L.; Miranda, J.D.; Leon, M.D. Docosahexaenoic acid pretreatment confers protection and functional improvements after acute spinal cord injury in adult rats. J. Neurotrauma 2012, 29, 551-566. [CrossRef] [PubMed]

39. Figueroa, J.D.; Cordero, K.; Llán, M.S.; De Leon, M. Dietary omega-3 polyunsaturated fatty acids improve the neurolipidome and restore the DHA status while promoting functional recovery after experimental spinal cord injury. J. Neurotrauma 2013, 30, 853-868. [CrossRef] [PubMed]

40. Figueroa, J.D.; Cordero, K.; Serrano-Illan, M.; Almeyda, A.; Baldeosingh, K.; Almaguel, F.G.; De Leon, M. Metabolomics uncovers dietary omega-3 fatty acid-derived metabolites implicated in anti-nociceptive responses after experimental spinal cord injury. Neuroscience 2013, 255, 1-18. [CrossRef] [PubMed] 
41. Saunders, R.D.; Dugan, L.L.; Demediuk, P.; Means, E.D.; Horrocks, L.A.; Anderson, D.K. Effects of methylprednisolone and the combination of alpha-tocopherol and selenium on arachidonic acid metabolism and lipid peroxidation in traumatized spinal cord tissue. J. Neurochem. 1987, 49, 24-31. [CrossRef] [PubMed]

42. Hall, E.D.; Wolf, D.L. A pharmacological analysis of the pathophysiological mechanisms of posttraumatic spinal cord ischemia. J. Neurosurg. 1986, 64, 951-961. [CrossRef] [PubMed]

43. Anderson, D.K.; Waters, T.R.; Means, E.D. Pretreatment with alpha tocopherol enhances neurologic recovery after experimental spinal cord compression injury. J. Neurotrauma 1988, 5, 61-67. [CrossRef] [PubMed]

44. Iwasa, K.; Ikata, T.; Fukuzawa, K. Protective effect of vitamin E on spinal cord injury by compression and concurrent lipid peroxidation. Free Radic. Biol. Med. 1989, 6, 599-606. [CrossRef]

45. Al Jadid, M.S.; Robert, A.; Al-Mubarak, S. The efficacy of alpha-tocopherol in functional recovery of spinal cord injured rats: An experimental study. Spinal Cord 2009, 47, 662-667. [CrossRef] [PubMed]

46. Robert, A.A.; Zamzami, M.; Sam, A.E.; Al Jadid, M.; Al Mubarak, S. The efficacy of antioxidants in functional recovery of spinal cord injured rats: An experimental study. Neurol. Sci. 2012, 33, 785-791. [CrossRef] [PubMed]

47. Bozbuga, M.; Izgi, N.; Canbolat, A. The effects of chronic alpha-tocopherol administration on lipid peroxidation in an experimental model of acute spinal cord injury. Neurosurg. Rev. 1998, 21, 36-42. [CrossRef] [PubMed]

48. Taoka, Y.; Ikata, T.; Fukuzawa, K. Influence of dietary vitamin E deficiency on compression injury of rat spinal cord. J. Nutr. Sci. Vitaminol. 1990, 36, 217-226. [CrossRef] [PubMed]

49. Sano, M.; Ernesto, C.; Thomas, R.G.; Klauber, M.R.; Schafer, K.; Grundman, M.; Woodbury, P.; Growdon, J.; Cotman, C.W.; Pfeiffer, E.; et al. A controlled trial of selegiline, alpha-tocopherol, or both as treatment for Alzheimer's disease. The Alzheimer's Disease Cooperative Study. N. Engl. J. Med. 1997, 336, 1216-1222. [CrossRef] [PubMed]

50. Evans, D.A.; Morris, M.C.; Rajan, K.B. Vitamin E, memantine, and Alzheimer disease. JAMA 2014, 311, 29-30. [CrossRef] [PubMed]

51. Dysken, M.W.; Sano, M.; Asthana, S.; Vertrees, J.E.; Pallaki, M.; Llorente, M.; Love, S.; Schellenberg, G.D.; McCarten, J.R.; Malphurs, J.; et al. Effect of vitamin E and memantine on functional decline in Alzheimer disease: The TEAM-AD VA cooperative randomized trial. JAMA 2014, 311, 33-44. [CrossRef] [PubMed]

52. Gruner, J.A. A monitored contusion model of spinal cord injury in the rat. J. Neurotrauma 1992, 9, 123-126, discussion 126-128. [CrossRef] [PubMed]

53. Pikov, V.; Gillis, R.A.; Jasmin, L.; Wrathall, J.R. Assessment of lower urinary tract functional deficit in rats with contusive spinal cord injury. J. Neurotrauma 1998, 15, 375-386. [CrossRef] [PubMed]

54. Kruse, M.N.; Belton, A.L.; de Groat, W.C. Changes in bladder and external urethral sphincter function after spinal cord injury in the rat. Am. J. Physiol. 1993, 264, R1157-R1163. [CrossRef] [PubMed]

55. Basso, D.M.; Beattie, M.S.; Bresnahan, J.C. A sensitive and reliable locomotor rating scale for open field testing in rats. J. Neurotrauma 1995, 12, 1-21. [CrossRef] [PubMed]

56. Atkins, D.M. Management of bladder dysfunction in cord injury. Rocky Mt. Med. J. 1961, 58, 30-31. [PubMed]

57. Cruz, C.D.; Cruz, F. Spinal cord injury and bladder dysfunction: New ideas about an old problem. Sci. World J. 2011, 11, 214-234. [CrossRef] [PubMed]

58. Jousse, A.T.; Geisler, W.O.; Wynne-Jones, M.; MacKay, I. The management of the spastic contracted bladder in spinal cord dysfunction. Proc. Annu. Clin. Spinal Cord Inj. Conf. 1966, 15, 140-151. [PubMed]

59. Shevtsov, I.P. On the problem of emptying the urinary bladder in patients with spinal cord injury. Voen. Med. Zhurnal 1967, 3, 80-81.

60. Campbell, E.W. Bladder dysfunction related to lesions of the spinal cord. South. Med. J. 1967, 60, 364-366. [CrossRef] [PubMed]

61. Damanski, M. Recovery of bladder function in paraplegia. Br. J. Surg. 1967, 54, 607-609. [CrossRef] [PubMed]

62. Tanoue, K. Experimental studies on the physiopathology of neurogenic bladder due to spinal cord injury, with special reference to the effect of drugs on the smooth muscle of the bladder in the acute stage. Hinyokika Kiyo 1969, 15, 321-336. [PubMed]

63. Hofman, P. Bladder behaviour following lesions of the cervical spinal cord. Acta Neurochir 1970, 22, 265-269. [PubMed]

64. Lee, J.K.; Emch, G.S.; Johnson, C.S.; Wrathall, J.R. Effect of spinal cord injury severity on alterations of the H-reflex. Exp. Neurol. 2005, 196, 430-440. [CrossRef] [PubMed] 
65. Antri, M.; Mouffle, C.; Orsal, D.; Barthe, J.Y. 5-HT1A receptors are involved in short- and long-term processes responsible for 5-HT-induced locomotor function recovery in chronic spinal rat. Eur. J. Neurosci. 2003, 18, 1963-1972. [CrossRef] [PubMed]

66. Antri, M.; Barthe, J.Y.; Mouffle, C.; Orsal, D. Long-lasting recovery of locomotor function in chronic spinal rat following chronic combined pharmacological stimulation of serotonergic receptors with 8-OHDPAT and quipazine. Neurosci. Lett. 2005, 384, 162-167. [CrossRef] [PubMed]

67. Barbeau, H.; Rossignol, S. Initiation and modulation of the locomotor pattern in the adult chronic spinal cat by noradrenergic, serotonergic and dopaminergic drugs. Brain Res. 1991, 546, 250-260. [CrossRef]

68. Eaton, M.J.; Pearse, D.D.; McBroom, J.S.; Berrocal, Y.A. The combination of human neuronal serotonergic cell implants and environmental enrichment after contusive SCI improves motor recovery over each individual strategy. Behav. Brain Res. 2008, 194, 236-241. [CrossRef] [PubMed]

69. Fouad, K.; Rank, M.M.; Vavrek, R.; Murray, K.C.; Sanelli, L.; Bennett, D.J. Locomotion after spinal cord injury depends on constitutive activity in serotonin receptors. J. Neurophysiol. 2010, 104, 2975-2984. [CrossRef] [PubMed]

70. Gerin, C.G.; Hill, A.; Hill, S.; Smith, K.; Privat, A. Serotonin release variations during recovery of motor function after a spinal cord injury in rats. Synapse 2010, 64, 855-861. [CrossRef] [PubMed]

71. Harris-Warrick, R.M.; Cohen, A.H. Serotonin modulates the central pattern generator for locomotion in the isolated lamprey spinal cord. J. Exp. Biol. 1985, 116, 27-46. [PubMed]

72. Hains, B.C.; Johnson, K.M.; Eaton, M.J.; Willis, W.D.; Hulsebosch, C.E. Serotonergic neural precursor cell grafts attenuate bilateral hyperexcitability of dorsal horn neurons after spinal hemisection in rat. Neuroscience 2003, 116, 1097-1110. [CrossRef]

73. Hains, B.C.; Willis, W.D.; Hulsebosch, C.E. Serotonin receptors 5-HT1A and 5-HT3 reduce hyperexcitability of dorsal horn neurons after chronic spinal cord hemisection injury in rat. Exp. Brain Res. 2003, 149, 174-186. [CrossRef] [PubMed]

74. Kong, X.Y.; Wienecke, J.; Chen, M.; Hultborn, H.; Zhang, M. The time course of serotonin 2A receptor expression after spinal transection of rats: An immunohistochemical study. Neuroscience 2011, 177, 114-126. [CrossRef] [PubMed]

75. Murray, K.C.; Stephens, M.J.; Ballou, E.W.; Heckman, C.J.; Bennett, D.J. Motoneuron excitability and muscle spasms are regulated by 5-HT2B and 5-HT2C receptor activity. J. Neurophysiol. 2011, 105, 731-748. [CrossRef] [PubMed]

76. Murray, K.C.; Stephens, M.J.; Rank, M.; D'Amico, J.; Gorassini, M.A.; Bennett, D.J. Polysynaptic excitatory postsynaptic potentials that trigger spasms after spinal cord injury in rats are inhibited by 5-HT1B and 5-HT1F receptors. J. Neurophysiol. 2011, 106, 925-943. [CrossRef] [PubMed]

77. Kruse, M.N.; Bray, L.A.; de Groat, W.C. Influence of spinal cord injury on the morphology of bladder afferent and efferent neurons. J. Auton. Nerv. Syst. 1995, 54, 215-224. [CrossRef]

78. Karsenty, G.; Reitz, A.; Wefer, B.; Boy, S.; Schurch, B. Understanding detrusor sphincter dyssynergiasignificance of chronology. Urology 2005, 66, 763-768. [CrossRef] [PubMed]

79. Nadeau, G.; Schröder, A.; Moore, K.; Genois, L.; Lamontagne, P.; Hamel, M.; Pellerin, E.; Bolduc, S. Double anticholinergic therapy for refractory neurogenic and nonneurogenic detrusor overactivity in children: Long-term results of a prospective open-label study. Can. Urol. Assoc. J. 2014, 8, 175-180. [CrossRef] [PubMed]

80. Salcedo, C.; Davalillo, S.; Cabellos, J.; Lagunas, C.; Balsa, D.; Pérez-Del-Pulgar, S.; Ballarín, M.; Fernández, A. In vivo and in vitro pharmacological characterization of SVT-40776, a novel M3 muscarinic receptor antagonist, for the treatment of overactive bladder. Br. J. Pharmacol. 2009, 156, 807-817. [CrossRef] [PubMed]

81. Gillespie, J.I.; Palea, S.; Guilloteau, V.; Guerard, M.; Lluel, P.; Korstanje, C. Modulation of non-voiding activity by the muscarinergic antagonist tolterodine and the beta(3)-adrenoceptor agonist mirabegron in conscious rats with partial outflow obstruction. BJU Int. 2012, 110, E132-E142. [CrossRef] [PubMed]

82. Peterson, J.S.; Noronha-Blob, L. Effects of selective cholinergic antagonists and alpha,beta-methylene ATP on guinea-pig urinary bladder contractions in vivo following pelvic nerve stimulation. J. Auton. Pharmacol. 1989, 9, 303-313. [CrossRef] [PubMed]

83. Amend, B.; Hennenlotter, J.; Schäfer, T.; Horstmann, M.; Stenzl, A.; Sievert, K.D. Effective treatment of neurogenic detrusor dysfunction by combined high-dosed antimuscarinics without increased side-effects. Eur. Urol. 2008, 53, 1021-1028. [CrossRef] [PubMed] 
84. Horstmann, M.; Schaefer, T.; Aguilar, Y.; Stenzl, A.; Sievert, K.D. Neurogenic bladder treatment by doubling the recommended antimuscarinic dosage. Neurourol. Urodyn. 2006, 25, 441-445. [CrossRef] [PubMed]

85. Ethans, K.D.; Nance, P.W.; Bard, R.J.; Casey, A.R.; Schryvers, O.I. Efficacy and safety of tolterodine in people with neurogenic detrusor overactivity. J. Spinal Cord Med. 2004, 27, 214-218. [CrossRef] [PubMed]

86. Kim, J.H.; Rivas, D.A.; Shenot, P.J.; Green, B.; Kennelly, M.; Erickson, J.R.; O’Leary, M.; Yoshimura, N.; Chancellor, M.B. Intravesical resiniferatoxin for refractory detrusor hyperreflexia: A multicenter, blinded, randomized, placebo-controlled trial. J. Spinal Cord Med. 2003, 26, 358-363. [CrossRef] [PubMed]

87. Ahmed, S.; Yuan, J. Experimental study of the effect of capsaicin on the urinary bladder function in rats. J. Tongji Med. Univ. 2000, 20, 116-119. [PubMed]

88. Geirsson, G.; Fall, M.; Sullivan, L. Clinical and urodynamic effects of intravesical capsaicin treatment in patients with chronic traumatic spinal detrusor hyperreflexia. J. Urol 1995, 154, 1825-1829. [CrossRef]

89. Das, A.; Chancellor, M.B.; Watanabe, T.; Sedor, J.; Rivas, D.A. Intravesical capsaicin in neurologic impaired patients with detrusor hyperreflexia. J. Spinal Cord Med. 1996, 19, 190-193. [CrossRef] [PubMed]

90. De Seze, M.; Wiart, L.; Joseph, P.A.; Dosque, J.P.; Mazaux, J.M.; Barat, M. Capsaicin and neurogenic detrusor hyperreflexia: A double-blind placebo-controlled study in 20 patients with spinal cord lesions. Neurourol. Urodyn. 1998, 17, 513-523. [CrossRef]

91. Cruz, F. Desensitization of bladder sensory fibers by intravesical capsaicin or capsaicin analogs. A new strategy for treatment of urge incontinence in patients with spinal detrusor hyperreflexia or bladder hypersensitivity disorders. Int. Urogynecol. J. 1998, 9, 214-220. [CrossRef]

92. De Seze, M.; Wiart, L.; de Sèze, M.P.; Joseph, P.A.; Brochet, B.; Ferrière, J.M.; Mazaux, J.M.; Barat, M. Reiterated intravesical instillation of capsaicin in neurogenic detrusor hyperreflexia: A 5-years experience of 100 instillations. Ann. Readapt. Med. Phys. 2001, 44, 514-524. [PubMed]

93. Linsenmeyer, T.A.; Horton, J.; Benevento, J. Impact of alpha1-blockers in men with spinal cord injury and upper tract stasis. J. Spinal Cord Med. 2002, 25, 124-128. [CrossRef] [PubMed]

94. Andersson, K. alpha1-adrenoceptors and bladder function. Eur. Urol. 1999, 36, 96-102. [CrossRef] [PubMed]

95. Lee, J.Z.; Tillig, B.; Perkash, I.; Constantinou, C.E. Effect of alpha1 adrenoceptor antagonist on the urodynamics of the upper and lower urinary tract of the male rat. Neurourol. Urodyn. 1998, 17, 213-229. [CrossRef]

96. Markiewicz, W.; Jasiecka, A.; Barski, D.; Janiuk, J.; Bossowska, A.; Jaroszewski, J.J. The influence of doxazosin, an alpha1-adrenergic receptor antagonist on the urinary bladder contractility in pigs. Pol. J. Vet. Sci. 2014, 17, 527-529. [PubMed]

97. Usta, C.; Kukul, E.; Yalcinkaya, M. Doxazosin effects on cholinergic and adrenergic responses in rat isolated detrusor smooth muscle preparations from obstructed bladder. J. Pharmacol. Sci. 2004, 95, 305-310. [CrossRef] [PubMed]

98. Das, A.K.; Leggett, R.E.; Whitbeck, C.; Eagen, G.; Levin, R.M. Effect of doxazosin on rat urinary bladder function after partial outlet obstruction. Neurourol. Urodyn. 2002, 21, 160-166. [CrossRef] [PubMed]

99. Serels, S.; Stein, M. Prospective study comparing hyoscyamine, doxazosin, and combination therapy for the treatment of urgency and frequency in women. Neurourol. Urodyn. 1998, 17, 31-36. [CrossRef]

100. Miyazato, M.; Sugaya, K.; Nishijima, S.; Kadekawa, K.; Ashimine, S.; Ogawa, Y. Intrathecal or dietary glycine inhibits bladder and urethral activity in rats with spinal cord injury. J. Urol. 2005, 174, 2397-2400. [CrossRef] [PubMed]

101. Magora, F.; Shazar, N.; Drenger, B. Urodynamic studies after intrathecal administration of baclofen and morphine in dogs. J. Urol. 1989, 141, 143-147. [CrossRef]

102. Steers, W.D.; Meythaler, J.M.; Haworth, C.; Herrell, D.; Park, T.S. Effects of acute bolus and chronic continuous intrathecal baclofen on genitourinary dysfunction due to spinal cord pathology. J. Urol. 1992, 148, 1849-1855. [CrossRef]

103. Kilicarslan, H.; Ayan, S.; Vuruskan, H.; Gokce, G.; Gultekin, E.Y. Treatment of detrusor sphincter dyssynergia with baclofen and doxazosin. Int. Urol. Nephrol. 2006, 38, 537-541. [CrossRef] [PubMed]

104. Miyazato, M.; Sasatomi, K.; Hiragata, S.; Sugaya, K.; Chancellor, M.B.; de Groat, W.C.; Yoshimura, N. Suppression of detrusor-sphincter dysynergia by GABA-receptor activation in the lumbosacral spinal cord in spinal cord-injured rats. Am. J. Physiol. Regul. Integr. Comp. Physiol. 2008, 295, R336-R342. [CrossRef] [PubMed] 
105. Takeda, M.; Araki, I.; Mochizuki, T.; Nakagomi, H.; Kobayashi, H.; Sawada, N.; Zakohji, H. The forefront for novel therapeutic agents based on the pathophysiology of lower urinary tract dysfunction: Pathophysiology of voiding dysfunction and pharmacological therapy. J. Pharmacol. Sci. 2010, 112, 121-127. [CrossRef] [PubMed]

106. Kalinichev, M.; Palea, S.; Haddouk, H.; Royer-Urios, I.; Guilloteau, V.; Lluel, P.; Schneider, M.; Saporito, M.; Poli, S. ADX71441, a novel, potent and selective positive allosteric modulator of the GABA(B) receptor, shows efficacy in rodent models of overactive bladder. Br. J. Pharmacol. 2014, 171, 995-1006. [CrossRef] [PubMed]

107. Leippold, T.; Reitz, A.; Schurch, B. Botulinum toxin as a new therapy option for voiding disorders: Current state of the art. Eur. Urol. 2003, 44, 165-174. [CrossRef]

108. Gallien, P.; Robineau, S.; Verin, M.; Le Bot, M.P.; Nicolas, B.; Brissot, R. Treatment of detrusor sphincter dyssynergia by transperineal injection of botulinum toxin. Arch. Phys. Med. Rehabil. 1998, 79, 715-717. [CrossRef]

109. Giannantoni, A.; Mearini, E.; Del Zingaro, M.; Porena, M. Six-year follow-up of botulinum toxin A intradetrusorial injections in patients with refractory neurogenic detrusor overactivity: Clinical and urodynamic results. Eur. Urol. 2009, 55, 705-711. [CrossRef] [PubMed]

110. Smith, C.P.; Chancellor, M.B. Emerging role of botulinum toxin in the management of voiding dysfunction. J. Urol. 2004, 171, 2128-2137. [CrossRef] [PubMed]

111. Schurch, B. Botulinum toxin for the management of bladder dysfunction. Drugs 2006, 66, 1301-1318. [CrossRef] [PubMed]

112. Petit, H.; Wiart, L.; Gaujard, E.; Le Breton, F.; Ferrière, J.M.; Lagueny, A.; Joseph, P.A.; Barat, M. Botulinum A toxin treatment for detrusor-sphincter dyssynergia in spinal cord disease. Spinal Cord 1998, 36, 91-94. [CrossRef] [PubMed]

113. Cevik, O.; Erşahin, M.; Sener, T.E.; Tinay, I.; Tarcan, T.; Cetinel, S.; Sener, A.; Toklu, H.Z.; Sener, G. Beneficial effects of quercetin on rat urinary bladder after spinal cord injury. J. Surg. Res. 2013, 183, 695-703. [CrossRef] [PubMed]

114. Hess, M.J.; Hess, P.E.; Sullivan, M.R.; Nee, M.; Yalla, S.V. Evaluation of cranberry tablets for the prevention of urinary tract infections in spinal cord injured patients with neurogenic bladder. Spinal Cord 2008, 46, 622-626. [CrossRef] [PubMed]

115. Back, S.A.; Gan, X.; Li, Y.; Rosenberg, P.A.; Volpe, J.J. Maturation-dependent vulnerability of oligodendrocytes to oxidative stress-induced death caused by glutathione depletion. J. Neurosci. 1998, 18, 6241-6253. [PubMed]

116. Yonezawa, M.; Back, S.A.; Gan, X.; Rosenberg, P.A.; Volpe, J.J. Cystine deprivation induces oligodendroglial death: Rescue by free radical scavengers and by a diffusible glial factor. J. Neurochem. 1996, 67, 566-573. [CrossRef] [PubMed]

117. Nury, T.; Zarrouk, A.; Mackrill, J.J.; Samadi, M.; Durand, P.; Riedinger, J.M.; Doria, M.; Vejux, A.; Limagne, E.; Delmas, D. Induction of oxiapoptophagy on $158 \mathrm{~N}$ murine oligodendrocytes treated by 7-ketocholesterol-, 7beta-hydroxycholesterol-, or 24(S)-hydroxycholesterol: Protective effects of alpha-tocopherol and docosahexaenoic acid (DHA; C22:6 n-3). Steroids 2015, 99, 194-203. [CrossRef] [PubMed]

118. Nury, T.; Zarrouk, A.; Vejux, A.; Doria, M.; Riedinger, J.M.; Delage-Mourroux, R.; Lizard, G. Induction of oxiapoptophagy, a mixed mode of cell death associated with oxidative stress, apoptosis and autophagy, on 7-ketocholesterol-treated 158N murine oligodendrocytes: Impairment by alpha-tocopherol. Biochem. Biophys. Res. Commun. 2014, 446, 714-719. [CrossRef] [PubMed]

119. Ragot, K.; Delmas, D.; Athias, A.; Nury, T.; Baarine, M.; Lizard, G. alpha-Tocopherol impairs 7ketocholesterol-induced caspase-3-dependent apoptosis involving GSK-3 activation and Mcl-1 degradation on 158N murine oligodendrocytes. Chem. Phys. Lipids 2011, 164, 469-478. [CrossRef] [PubMed]

120. Reiber, H.; Martens, U.; Prall, F.; Uhr, M. Relevance of endogenous ascorbate and tocopherol for brain cell vitality indicated by photon emission. J. Neurochem. 1994, 62, 608-614. [CrossRef] [PubMed]

121. Bjartmar, C.; Trapp, B.D. Axonal and neuronal degeneration in multiple sclerosis: Mechanisms and functional consequences. Curr. Opin. Neurol. 2001, 14, 271-278. [CrossRef] [PubMed]

122. Blight, A.R. Remyelination, revascularization, and recovery of function in experimental spinal cord injury. Adv. Neurol. 1993, 59, 91-104. [PubMed] 
123. Valdovinos, B.D.; Jimenez, J.M.D.; Estrada, I.J.; Pineda, J.B.; Rodriguez, N.E.F.; Ruiz, J.R.L.; Carrasco, L.P.O.; Arellano, A.C.; Jimenez, S.H.D. Tamoxifen Promotes Axonal Preservation and Gait Locomotion Recovery after Spinal Cord Injury in Cats. J. Vet. Med. 2016, 2016, 9561968.

124. Jeffery, N.D.; Blakemore, W.F. Locomotor deficits induced by experimental spinal cord demyelination are abolished by spontaneous remyelination. Brain 1997, 120, 27-37. [CrossRef] [PubMed]

125. Jeffery, N.D.; Crang, A.J.; O’leary, M.T.; Hodge, S.J.; Blakemore, W.F. Behavioural consequences of oligodendrocyte progenitor cell transplantation into experimental demyelinating lesions in the rat spinal cord. Eur. J. Neurosci. 1999, 11, 1508-1514. [CrossRef]

126. Qiu, X.C.; Jin, H.; Zhang, R.Y.; Ding, Y.; Zeng, X.; Lai, B.Q.; Ling, E.A.; Wu, J.L.; Zeng, Y.S. Donor mesenchymal stem cell-derived neural-like cells transdifferentiate into myelin-forming cells and promote axon regeneration in rat spinal cord transection. Stem Cell Res. Ther. 2015, 6, 105. [CrossRef] [PubMed]

127. Lee, Y.S.; Lin, C.Y.; Robertson, R.T.; Yu, J.; Deng, X.; Hsiao, I.; Lin, V.W. Re-growth of catecholaminergic fibers and protection of cholinergic spinal cord neurons in spinal repaired rats. Eur J. Neurosci. 2006, 23, 693-702. [CrossRef] [PubMed]

128. DePaul, M.A.; Lin, C.Y.; Silver, J.; Lee, Y.S. Peripheral Nerve Transplantation Combined with Acidic Fibroblast Growth Factor and Chondroitinase Induces Regeneration and Improves Urinary Function in Complete Spinal Cord Transected Adult Mice. PLoS ONE 2015, 10, e0139335. [CrossRef] [PubMed]

129. Mitsui, T.; Neuhuber, B.; Fischer, I. Acute administration of AMPA/Kainate blocker combined with delayed transplantation of neural precursors improves lower urinary tract function in spinal injured rats. Brain Res. 2011, 1418, 23-31. [CrossRef] [PubMed]

130. Chang, H.Y.; Cheng, C.L.; Chen, J.J.; de Groat, W.C. Serotonergic drugs and spinal cord transections indicate that different spinal circuits are involved in external urethral sphincter activity in rats. Am. J. Physiol. Ren. Physiol. 2007, 292, F1044-F1053. [CrossRef] [PubMed]

131. White, S.R.; Vyas, D.; Bieger, D. Serotonin immunoreactivity in spinal cord axons and terminals of rodents with experimental allergic encephalomyelitis. Neuroscience 1985, 16, 701-709. [CrossRef]

132. Sandyk, R. Serotonergic neuronal atrophy with synaptic inactivation, not axonal degeneration, are the main hallmarks of multiple sclerosis. Int. J. Neurosci. 1998, 95, 133-140. [CrossRef] [PubMed]

133. Hashimoto, T.; Fukuda, N. Contribution of serotonin neurons to the functional recovery after spinal cord injury in rats. Brain Res. 1991, 539, 263-270. [CrossRef]

134. Saruhashi, Y.; Young, W.; Perkins, R. The recovery of 5-HT immunoreactivity in lumbosacral spinal cord and locomotor function after thoracic hemisection. Exp. Neurol. 1996, 139, 203-213. [CrossRef] [PubMed] 